\title{
Conditioned medium from activated spleen cells supports the survival of rat retinal cells in vitro
}

\section{A. Sholl-Franco ${ }^{1,2}$ and E.G. Araujo ${ }^{1}$}

\author{
1Departamento de Neurobiologia, Instituto de Biologia, \\ Universidade Federal Fluminense, Niterói, RJ, Brasil \\ ${ }^{2}$ Instituto de Biofísica Carlos Chagas Filho, Centro de Ciências da Saúde, \\ Universidade Federal do Rio de Janeiro, Rio de Janeiro, RJ, Brasil
}

\author{
Correspondence \\ A. Sholl-Franco \\ Departamento de Neurobiologia \\ Instituto de Biologia, UFF \\ Caixa Postal 100180 \\ 24001-970 Niterói, RJ \\ Brasil \\ Fax: 55 (021) 719-5934 \\ E-mail: adrianno@openlink.com.br \\ Research supported by CAPES, \\ CEG-UFF, FAPERJ and FINEP. \\ A. Sholl-Franco is the recipient \\ of a CAPES fellowship.
}

Received May 13, 1997

Accepted September 9, 1997

\begin{abstract}
Cytokines are a heterogeneous group of molecules that have been associated with several functions in the nervous system, such as survival and differentiation of neuronal and glial cells. In the present study, we demonstrated that conditioned medium from spleen cells activated with concanavalin A increased neuritogenesis and survival of retinal cells, as measured by biochemical and morphological criteria. Our data showed that conditioned medium induced a five-fold
\end{abstract}

Key words - Cytokines - Growth factor

- Neuroimmunology

- Retina

- Development
The growth, differentiation, survival, and death of neuronal cells can be modulated by specific molecules produced during the normal development of the nervous system (1). Over the last few years it has been demonstrated that molecules produced by cells of the immune system can affect different neuronal populations as well as glial cells $(2,3)$. In addition, glial cells have been shown to produce and release at least some of these molecules (4).

Cytokines are molecules with pleiotropic effects originally described as having immunoregulatory functions $(5,6)$. However, it is their action on the nervous system as neurotrophic and differentiation factors that is presently well known $(2,6)$. Various effects of cytokines on the nervous system have been described including neuronal survival and differentiation, neurite outgrowth, synaptic plasticity, modulation of neurotransmitter systems and hormonal regulation $(1,3,7)$. Cytokines are a heterogeneous group of molecules including trophic factors, interleukins and other factors with the ability of inducing differentiation of specific cell populations $(5,7)$. Cytokines also have an important role in inflammatory processes and in 
conditions following neuronal injuries in adult life $(2,5,6)$.

To test the action of cytokines on neurons in the developing central nervous system, we have studied a particularly wellcharacterized region, the neural retina. In the present study, we investigated the effect of conditioned medium produced by spleen cells activated with concanavalin A (ConA) on retinal cells in culture. When spleen cells are activated with ConA they produce a broad spectrum of growth-promoting factors such as colony-stimulating factors, interleukins, and a nerve growth factor-related molecule (8-10). The present results suggest that these cytokines can promote neuronal survival and neurite outgrowth in dissociated cultures of newborn rat retinal cells, as evaluated by both morphological criteria and protein assays. Our data indicate that these molecules may have important roles in neuronal and glial development.

Primary cultures were prepared using procedures previously described (11). Briefly, Lister Hooded rats at postnatal day 1 or 2 were killed by decapitation and the retinas were dissected free from scleral tissue and pigmented epithelium in calcium- and magnesium-free balanced salt solution (CMF). The retinas were incubated in CMF containing $0.1 \%$ trypsin (Worthington, Freehold, $\mathrm{NJ}$ ) for approximately $17 \mathrm{~min}$ at $37^{\circ} \mathrm{C}$. The cells were mechanically dissociated using a polished Pasteur pipette and added to plastic Petri dishes $(35 \mathrm{~mm})$ previously coated with poly-L-ornithine $(50 \mu \mathrm{g} / \mathrm{ml}$; Sigma Chemical Co., St. Louis, MO) at a plating density of $1.0 \times 10^{6}$ cells/dish in complete culture medium (199; Gibco, Gaithersburg, MD) containing $2 \mathrm{mM}$ glutamine, $100 \mu \mathrm{g} / \mathrm{ml}$ streptomycin $+100 \mathrm{U} / \mathrm{ml}$ penicillin (Sigma) and 5\% fetal calf serum. The cultures were then maintained at $37^{\circ} \mathrm{C}$ in an atmosphere of $5 \% \mathrm{CO}_{2} /$ 95\% air for several days. The conditioned medium (CM) obtained from ConA-activated spleen cells was prepared by the method of Gozes et al. (9) modified in our laboratory.
Briefly, adult Lister Hooded rats were killed by ether asphyxia and the spleens were dissected in CMF solution. The single-cell suspension was obtained by passing spleens through a 50-gauge plastic mesh. The culture medium containing the cells was left to rest for $1 \mathrm{~h}$ on plastic dishes $(35 \mathrm{~mm})$ in order to allow the attachment of macrophages. The supernatant containing the non-adherent cells was aspirated, centrifuged (2000 $\mathrm{g}$ for $5 \mathrm{~min}$ ), and added at a plating density of $5.0 \times 10^{6}$ cells $/ \mathrm{ml}$ to complete culture medium supplemented with 2-mercaptoethanol $(25 \mu \mathrm{M})$ and ConA $(5.0 \mu \mathrm{g} / \mathrm{ml})$ for approximately $12 \mathrm{~h}$ at $37^{\circ} \mathrm{C}$ in an atmosphere of $5 \%$ $\mathrm{CO}_{2} / 95 \%$ air. The supernatant thus obtained was again centrifuged at $2000 \mathrm{~g}$ for $10 \mathrm{~min}$ and the $\mathrm{CM}$ was sterilized by filtration through a $0.2-\mu \mathrm{m}$ membrane and kept at $4^{\circ} \mathrm{C}$. After the maintenance of retinal cells in culture for specific times, the morphology of the culture was analyzed and the total amount of protein in the cultures quantified by the method of Lowry et al. (12).

Figure 1 shows that CM kept cultured retinal cells viable for at least $120 \mathrm{~h}$ whereas pre-coating of culture dishes with $\mathrm{CM}$ did not elicit the same effect, suggesting that only soluble factors are involved (data not shown). Similarly, treatment with ConA alone did not affect the viability of retinal cells (data not shown), while CM maintained the survival of retinal cells. The action of $\mathrm{CM}$ on the morphology of retinal cells was first observed in vitro after $48 \mathrm{~h}$ (Figure 1B). Some changes in cell morphology were already observed after this time, with an increase in the number of small clusters of neuronal and glial cells (Figure 1B). The number of cell-bearing processes was also increased when compared with control cultures (Figure 1A,B). However, after $48 \mathrm{~h}$ the amount of protein in cultures treated with $\mathrm{CM}(103.51 \pm 4.11 \mu \mathrm{g}$ protein/Petri dish $)$ was not different from that observed in control cultures $(109.45 \pm 4.82 \mu \mathrm{g}$ protein/Petri dish). After $120 \mathrm{~h}$ of incubation with CM the 

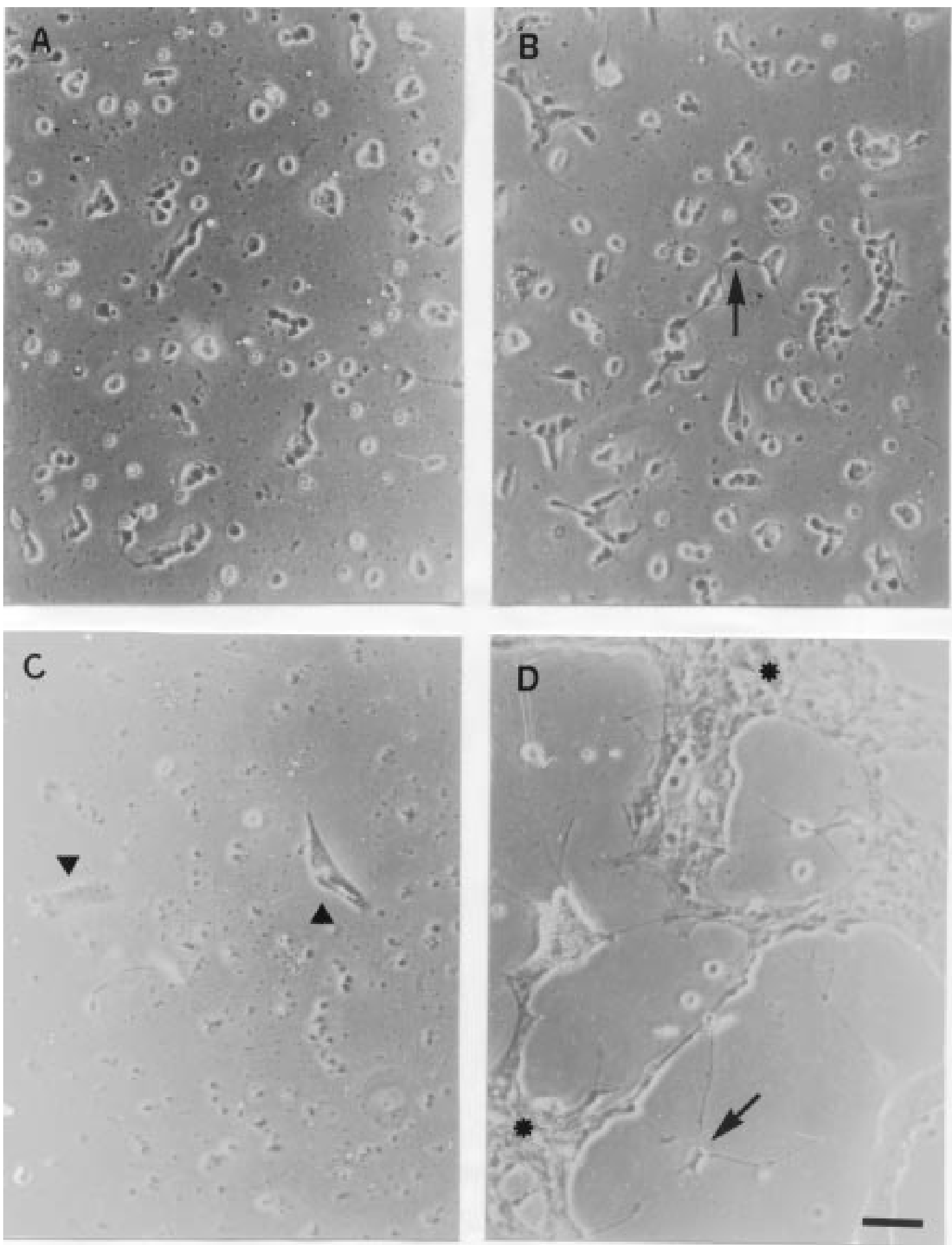

Figure 1 - Phase contrast photomicrographs of retinal cells in vitro. Cells were dissociated from neonatal rat retina and cultured for $48(\mathrm{~A}$ and $\mathrm{B})$ and $120 \mathrm{~h}(\mathrm{C}$ and $\mathrm{D})$. $A$ and $C$, Control cultures; $B$ and $D$, cultures maintained in the presence of conditioned medium (1:10). The plating density was $1.3 \times 10^{6} \mathrm{cells} / \mathrm{dish}$. Note the presence of isolated neuronal cells with long neurites (arrows) and flat-shaped glial cells (arrowheads) in the cultures. Extensive clusters of neuronal and glial cells are indicated by asterisks. Magnification bar for all photomicrographs: $50 \mu \mathrm{m}$. 
Figure 2 - Histograms showing the protein content of retinal cultures. $A$, The cells were incubated for $120 \mathrm{~h}$ with control medium (control), conditioned medium (CM; 1:10), $5.0 \mu \mathrm{M}$ nifedipine or nifedipine $+\mathrm{CM}$. $B$, The cells were incubated for $96 \mathrm{~h}$ with control medium (control), conditioned medium (CM; 1:10), $15.0 \mu \mathrm{M}$ BAPTA-AM or BAPTA$A M+C M$. Data are reported as the mean \pm SEM of 3 independent experiments, each performed in triplicate.
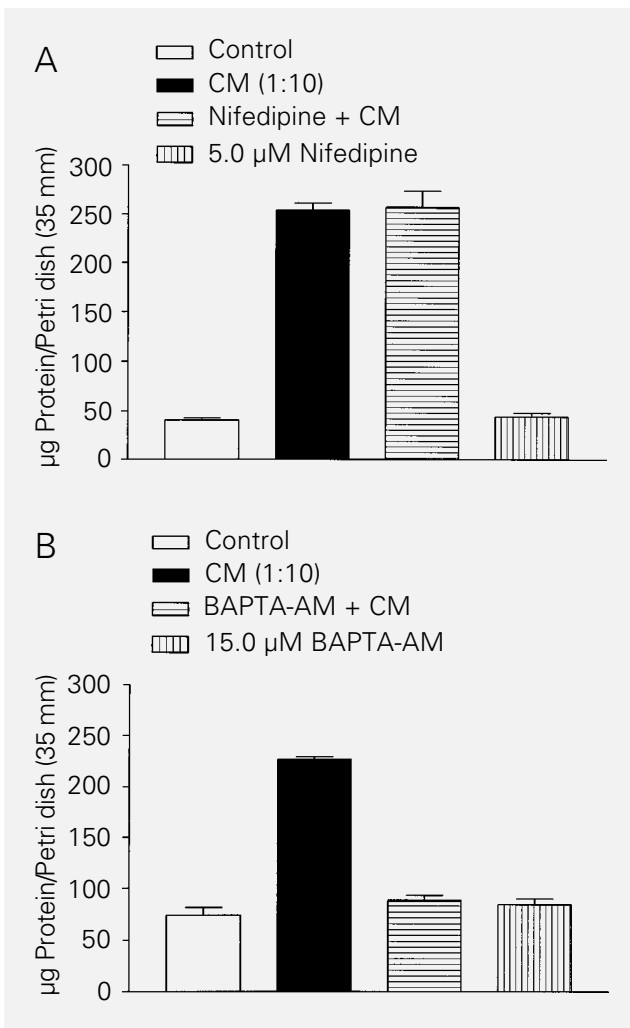

presence of large clusters of neuronal cells supported by glial cells was clearly visible. Neuritogenesis, neuronal survival as well as glial cell proliferation were highly stimulated by $\mathrm{CM}$ (Figure 1D). The cells maintained in the absence of $\mathrm{CM}$ died within $120 \mathrm{~h}$ as observed by morphological criteria, i.e., shrinkage of the body of neuronal cells and disruption of neuronal processes (Figure 1C). In the control cultures there were only glial cells that took on a flat shape characteristic of this cell type (Figure 1C).

As shown in Figure 2A, CM also increased the amount of protein compared with control cultures. The increase in protein in treated cultures reflects not only the proliferation of glial cells but also the survival of neuronal cells. In fact, the use of the antimitotic agent 2-fluorodeoxyuridine $(20.0 \mu \mathrm{M})$ did not block the survival or neuritogenesis of neuronal cells stimulated with CM (data not shown).

The maintenance of retinal cells in culture by the treatment with $\mathrm{CM}$ was dose- dependent and heat-sensitive, and was observed at all plating densities studied (data not shown). Moreover, the blockade of voltage-dependent L-type calcium channels with nifedipine $(5.0 \mu \mathrm{M})$ did not inhibit the action of CM on retinal cells (Figure 2A). On the other hand, it appears that the cytoplasmic calcium levels were essential for the effect of CM since BAPTA-AM $(15.0 \mu \mathrm{M})$, an intracellular calcium chelator, was efficient in blocking the increase in the amount of protein (Figure 2B).

The regulation of cytoplasmic calcium levels has been described in different events during the development, maintenance, and degeneration of neuronal cells. This intracellular messenger actively participates in several signaling pathways in the membrane and in the cytoplasm. Indeed, the survival of developing neuronal cells deprived of trophic factors in culture has been related to the control of cytoplasmic levels of free calcium (13). Our results show that this second messenger is important for the action of $\mathrm{CM}$ since the addition of BAPTA-AM completely abolished this action. Nevertheless, the blockade of voltage-dependent L-type calcium channels did not alter the effect of CM, even though the influx of calcium through these channels is known to play a key role in the survival of other neuronal cell types $(13,14)$.

While most of the reported effects of cytokines are on non-neuronal cells, there is also evidence that they may directly act on neurons $(3,4,15,16)$. In addition, the early time course of the expression of some cytokines suggests that these molecules may have important effects on neuronal differentiation $(1,7,16,17)$.

Although the retina has been extensively studied by anatomical, histological and biochemical methods, there is still very little information concerning the mechanisms that control its development leading to cellular differentiation. Strong evidence suggests that the development of retinal cells is regulated by cell-cell contacts and by diffusible mol- 
ecules $(4,11,18)$.

In general, cytokines produced and secreted by lymphocytes are related to inflammatory and degenerative processes $(2,5,6)$. It is well known that lymphoid cells also have the ability to secrete growth-promoting factors that participate in a pleiotropic manner in the development of the nervous system and in its protection against pathological conditions $(1,9,15,17)$. Our results support the idea that molecules secreted by activated lymphocytes can modulate the maintenance and differentiation of rat retinal cells in vitro, indicating a possible role of these molecules in the development of retinal cells.

\section{Acknowledgments}

We acknowledge the technical assistance of Alexandre José Fernandes and Bernardino Matheus dos Santos.

\section{References}

1. Korshing S (1993). The neurotrophic factor concept: a reexamination. Journal of Neuroscience, 13: 2739-2748.

2. Hopkins SJ \& Rothwell NJ (1995). Cytokines and the nervous system. I. Expression and recognition. Trends in Neurosciences, 18: 83-88.

3. Pousset F (1994). Cytokines as mediators in the central nervous system. Biomedicine and Pharmacotherapy, 48: 425-431.

4. Puro DG (1995). Growth factors and Müller cells. Progress in Retinal and Eye Research, 15: 89-101

5. Holtmann H \& Resch K (1995). Cytokines. Naturwissenschaften, 82: 178-187.

6. Rothwell NJ \& Hopkins SJ (1995). Cytokines and the nervous system. II. Actions and mechanisms of action. Trends in Neurosciences, 18: 130-136.

7. Patterson PH (1993). Cytokines and the function of the mature nervous system. Science de la Vie, 316: 1150-1157

8. Watson T, Aarden L \& Lefkovits I (1979). The purification and quantitation of helper $T$ cell replacing factors secreted by concanavalin A activated murine spleen cells. Journal of Immunology, 122: 209-215.
9. Gozes $Y$, Moskowitz MA, Strom TB \& Gozes I (1983). Conditioned media from activated lymphocytes maintain sympathetic neurons in culture. Developmental Brain Research, 6: 93-97.

10. Ganea D \& Sun L (1993). Vasoactive intestinal peptide downregulates the expression of IL-2 but not of INF $\gamma$ from stimulated murine T lymphocytes. Journal of $\mathrm{Neu}$ roimmunology, 47: 147-158.

11. Araujo EG \& Linden R (1993). Trophic factors produced by retinal cells increase the survival of retinal ganglion cells in vitro. European Journal of Neuroscience, 5: 1181-1188.

12. Lowry $\mathrm{OH}$, Rosebrough NJ, Farr $\mathrm{AC}$ \& Randall RJ (1951). Protein measurement with the Folin phenol reagent. Journal of Biological Chemistry, 193: 265-275.

13. Franklin JL \& Johnson Jr EM (1992). Suppression of programmed neuronal death by sustained elevation of cytoplasmic calcium. Trends in Neurosciences, 15: 501508.
14. Collins F \& Lile JD (1989). The role of dihydropyridine-sensitive voltage-gated calcium channels in potassium mediated neuronal survival. Brain Research, 502: 99-108.

15. Araujo DM \& Cotman CW (1993). Trophic effects of interleukin-4, -7 , and -8 on hippocampal neuronal cultures: potential involvement of glia-derived factors. Brain Research, 600: 49-55.

16. Konishi Y, Kamegai M, Takahashi K, Kunishita T \& Tabira T (1994). Production of interleukin-3 by murine central nervous system neurons. Neuroscience Letters, 182: $271-274$

17. Wagner JA (1996). Is IL-6 both a cytokine and a neurotrophic factor? Journal of EXperimental Medicine, 183: 2417-2419.

18. Watanabe T \& Raff MC (1990). Rod photoreceptor development in vitro: intrinsic properties of proliferating neuroepithelial cells change as development proceeds in the rat retina. Neuron, 4: 461-467. 